\title{
Ancient divergence time estimates in Eutropis rugifera support the existence of Pleistocene barriers on the exposed Sunda Shelf
}

\author{
Benjamin R Karin ${ }^{\text {Corresp., }}{ }^{1,2}{ }^{\text {， Indraneil Das }}{ }^{3}$, Todd R Jackman $^{1}$, Aaron M Bauer ${ }^{1}$ \\ 1 Department of Biology, Villanova University, Villanova, PA, United States \\ 2 Museum of Vertebrate Zoology and Department of Integrative Biology, University of California, Berkeley, Berkeley, CA, United States \\ 3 Institute of Biodiversity and Environmental Conservation, Universiti Malaysia Sarawak, Kota Samarahan, Sarawak, Malaysia \\ Corresponding Author: Benjamin R Karin \\ Email address: benrkarin@gmail.com
}

Episodic sea level changes that repeatedly exposed and inundated the Sunda Shelf characterize the Pleistocene. Available evidence points to a more xeric central Sunda Shelf during periods of low sea levels, and despite the broad land connections that persisted during this time, some organisms are assumed to have faced barriers to dispersal between land-masses on the Sunda Shelf. Eutropis rugifera is a secretive, forest adapted scincid lizard that ranges across the Sunda Shelf. In this study, we sequenced one mitochondrial (ND2) and four nuclear (BRCA1, BRCA2, RAG1, and MC1R) markers and generated a timecalibrated phylogeny in BEAST to test whether divergence times between Sundaic populations of $E$. rugifera occurred during Pleistocene sea-level changes, or if they predate the Pleistocene. We find that E. rugifera shows pre-Pleistocene divergences between populations on different Sundaic land-masses. The earliest divergence within $E$. rugifera separates the Philippine samples from the Sundaic samples approximately $16 \mathrm{Ma}$; the Philippine populations thus cannot be considered conspecific with Sundaic congeners. Sundaic populations diverged approximately $6 \mathrm{Ma}$, and populations within Borneo from Sabah and Sarawak separated approximately 4.5 Ma in the early Pliocene, followed by further cladogenesis in Sarawak through the Pleistocene. Divergence of peninsular Malaysian populations from the Mentawai Archipelago occurred approximately $5 \mathrm{Ma}$. Separation among island populations from the Mentawai Archipelago likely dates to the Pliocene/Pleistocene boundary approximately 3.5 Ma, and our samples from peninsular Malaysia appear to coalesce in the middle Pleistocene, about $1 \mathrm{Ma}$. Coupled with the monophyly of these populations, these divergence times suggest that despite consistent land-connections between these regions throughout the Pleistocene E. rugifera still faced barriers to dispersal, which may be a result of environmental shifts that accompanied the sea-level changes. 


\section{Ancient divergence time estimates in Eutropis rugifera}

\section{2 support the existence of Pleistocene barriers on the exposed}

3 Sunda Shelf

4

5 Benjamin R. Karin ${ }^{1,2}$, Indraneil Das ${ }^{3}$, Todd R. Jackman ${ }^{1}$, Aaron M. Bauer ${ }^{1}$

6

$7 \quad{ }^{1}$ Department of Biology, Villanova University, Villanova, PA 19085, USA.

$8{ }^{2}$ Museum of Vertebrate Zoology and Department of Integrative Biology, University of

9 California, Berkeley, CA 97420, USA.

$10{ }^{3}$ Institute of Biodiversity and Environmental Conservation, Universiti Malaysia Sarawak, 94300

11 Kota Samarahan, Sarawak, Malaysia.

12

13 Corresponding Author:

14 Benjamin Karin ${ }^{2}$

15

16 Email address: benkarin@berkeley.edu 


\section{Abstract}

19 Episodic sea level changes that repeatedly exposed and inundated the Sunda Shelf characterize

20 the Pleistocene. Available evidence points to a more xeric central Sunda Shelf during periods of

21 low sea levels, and despite the broad land connections that persisted during this time, some

22 organisms are assumed to have faced barriers to dispersal between land-masses on the Sunda

23 Shelf. Eutropis rugifera is a secretive, forest adapted scincid lizard that ranges across the Sunda

24 Shelf. In this study, we sequenced one mitochondrial (ND2) and four nuclear (BRCA1, BRCA2,

$25 R A G 1$, and $M C 1 R$ ) markers and generated a time-calibrated phylogeny in BEAST to test whether

26 divergence times between Sundaic populations of E. rugifera occurred during Pleistocene sea-

27 level changes, or if they predate the Pleistocene. We find that E. rugifera shows pre-Pleistocene

28 divergences between populations on different Sundaic land-masses. The earliest divergence

29 within E. rugifera separates the Philippine samples from the Sundaic samples approximately 16

$30 \mathrm{Ma}$; the Philippine populations thus cannot be considered conspecific with Sundaic congeners.

31 Sundaic populations diverged approximately $6 \mathrm{Ma}$, and populations within Borneo from Sabah

32 and Sarawak separated approximately 4.5 Ma in the early Pliocene, followed by further

33 cladogenesis in Sarawak through the Pleistocene. Divergence of peninsular Malaysian

34 populations from the Mentawai Archipelago occurred approximately $5 \mathrm{Ma}$. Separation among

35 island populations from the Mentawai Archipelago likely dates to the Pliocene/Pleistocene

36 boundary approximately 3.5 Ma, and our samples from peninsular Malaysia appear to coalesce

37 in the middle Pleistocene, about 1 Ma. Coupled with the monophyly of these populations, these

38 divergence times suggest that despite consistent land-connections between these regions 
39 throughout the Pleistocene E. rugifera still faced barriers to dispersal, which may be a result of 40 environmental shifts that accompanied the sea-level changes. 
41

42

43

44

45

46

47

48

49

50

51

52

53

54

55

56

57

58

59

60

61

62

63

\section{Introduction}

2

Throughout the Pleistocene and late Pliocene, glaciation cycles caused sea level fluctuations that repeatedly led to land connections between islands that today are separated by ocean channels (Miller et al., 2005). With these land connections, populations of terrestrial organisms that may have started to diverge on the separated landmasses have an opportunity to reconnect. Notable global cases (and examples of investigations of faunal divergence between the landmasses) include the reconnection of Taiwan with mainland Asia (Oshida et al., 2017), Tasmania with Australia (Dubey et al., 2010), Sri Lanka with India (Bossuyt et al., 2004; Bauer et al., 2010), Japan and the Ryukyus with east Asia (Ota, 1998; Qi et al., 2014) and islands of New Zealand with one another (Greaves et al., 2008). In some cases, divergence between allopatric populations may continue to accumulate despite land connection, and in other cases populations may fully reintegrate into panmixia. The likelihood that the populations of an organism will reconnect or remain divergent is determined by the dispersal capability of the organism across the exposed land-bridge, which is affected by the unique ecologic and geographic forces that exist in that region. These biogeographic drivers are an active area of research in homologous systems affected by sea level fluctuations (e.g., the Philippines, see Brown et al., 2013 for review).

9 The historic sea level fluctuations on the Sunda Shelf represent a dramatic case of an ever-changing Pleistocene landscape. Sea levels dropped $120 \mathrm{~m}$ below present levels and caused land area on the Sunda Shelf to expand up to twice the present area, leading to concomitant climatic and environmental changes (Cannon, Morley \& Bush, 2009). Sea levels were consistently lower (on average $62 \mathrm{~m}$ below present levels over the past $1 \mathrm{Ma}$ ) than today 
64 throughout the Pleistocene, during which about 58 glaciation events occurred, usually every 50-

$65100 \mathrm{ka}$, that allowed for broad land connections between the present-day landmasses (Voris,

66 2000; Sathiamurthy \& Voris, 2006; Woodruff \& Turner, 2009). Thus, the forest distributions and

67 island positions and connections on the Sunda Shelf during interglacial periods of high sea

68 levels, such as the present, represent the exception rather than the norm (Cannon, Morley \&

69 Bush, 2009). With these broad land connections so consistently bridging the islands, one would

70 predict that for widespread species divergence times between populations across the Sunda Shelf

71 will date back to one of the sea level reductions during the last 2.9 Ma when gene flow would

72 have been likely between the populations (Woodruff \& Turner, 2009). This pattern of late-

73 Pleistocene divergence for populations across the Sunda Shelf has been observed in several birds

74 and some reptiles (Lim et al., 2011; Grismer et al., 2015). However, older divergence times

75 predating these Plio-Pleiostocene land connections have been found in several mammals (e.g.,

76 Gorog, Sinaga \& Engstrom, 2004; Steiper, 2006; den Tex et al., 2010), suggesting that barriers

77 may have existed on the exposed Sunda Shelf.

78 The rough-scaled sun skink, Eutropis rugifera (Stoliczka, 1870), is a secretive, semi-

79 arboreal skink, distributed over mainland Southeast Asia (Peninsular Malaysia and southern

80 Thailand), as well as on the islands of Borneo, Sumatra, Java, Bali, the Nicobar Islands, the

81 Mentawai archipelago, and the southwest Philippines (Das, 2010; see Fig. 1). Barley et al. (2015)

82 and Amarasinghe et al. (2017) reported E. rugifera from Sulawesi in error based on samples

83 from the Mentawai archipelago that Barley et al. incorrectly attributed to Sulawesi. Inhabiting

84 low and mid elevation rainforests as well as peat swamps, E. rugifera is the most arboreal

85 Eutropis on Sundaland and, although generally terrestrial, has also been found up to a height of 2 
$86 \mathrm{~m}$ on tree trunks (Das, 2004). Eutropis rugifera is also one of the more enigmatic species of

87 Eutropis, with relatively few museum specimens collected and little known of its natural history. As Eutropis rugifera is present on the four largest Sundaic landmasses (Borneo, Sumatra,

Java, and Peninsular Malaysia), it represents an ideal biological system for testing hypotheses of divergence and diversification on the Sunda Shelf. Sea level and climatological shifts have impacted the landscape dramatically. It is estimated that Borneo was connected to the Malay Peninsula throughout the Miocene, and to Java and Sumatra as well after their emergence in the mid-Miocene $(\sim 10-15 \mathrm{Ma})$. These broad land connections on the Sunda Shelf persisted until the early Pliocene ( $\sim \mathrm{Ma})$ when sea level shifts caused fragmentation of these islands to nearpresent configurations, though there is likely to have been occasional land connections due to sea-level shifts throughout the Pliocene (Gorog, Sinaga \& Engstrom, 2004; Hall, 2009; Woodruff \& Turner, 2009). From the mid-Miocene to the mid-Pliocene, the climate is predicted to have remained relatively humid and moist, with tropical rainforest blanketing the Sunda Shelf. However, a global cooling event in the late Pliocene ( 3.3 to $2.5 \mathrm{Ma})$ caused substantial aridification that likely led to increased grassland on the Sunda Shelf and fragmentation of habitat (Dersch \& Stein, 1994; Gorog, Sinaga \& Engstrom, 2004; Miller et al., 2005). At the end of the Pliocene and throughout the Pleistocene, the frequency of rapid sea-level shifts increased dramatically, with land-masses on the Sunda Shelf consistently connected during sea-level drops of $>40 \mathrm{~m}$ (Voris, 2000; Woodruff \& Turner, 2009). Despite the consistency of land connections on the Sunda Shelf within the last $3 \mathrm{Ma}$, there is evidence that during these periods of land connections the central Sunda Shelf was relatively more xeric than at present and comprised chiefly savannah habitat (Bird, Taylor \& Hunt, 2005; Cannon, Morley \& Bush, 2009) that could have prevented dispersal of rainforest adapted taxa. Molecular analyses in mammals (Gorog, 
109 Sinaga \& Engstrom, 2004) and birds (Lim et al., 2011) support the presence of barriers to

110 dispersal on the exposed Sunda Shelf, although other evidence suggests a heterogeneous

111 landscape (see Louys \& Meijaard, 2010).

112 Previous phylogenetic studies have included broad enough geographic sampling for $E$.

113 rugifera to allow for a minimal assessment of phylogeographic patterns, but not to test the

114 drivers of divergence within the species. An initial phylogenetic study of Eutropis found little

115 molecular divergence in E. rugifera across three localities in Indonesia (Mausfeld \& Schmitz,

116 2003). Adding to this dataset, topotypic material from the Nicobar Islands was found to show

117 moderate molecular mitochondrial divergence from Sundaic (Bali and Sumatra) E. rugifera

118 (mean uncorrected p-distance 4.6\% for 12s; $2.5 \%$ for $16 \mathrm{~s}$; Datta-Roy et al. 2012). Amarasinghe

119 et al. (2017) included additional samples from Bali and from Bawean island to the north of Java,

120 uncovering these populations as separate and divergent lineages. Increased divergence is

121 common in island populations, and this level of divergence was not considered substantial

122 enough to distinguish these populations as separate species. Using unique molecular markers and

123 samples, Barley et al. (2015) recovered Sundaic populations (Borneo, Peninsular Malaysia, and

124 from Pulau Siberut, off the west coast of Sumatra) forming a clade that was highly divergent

125 (15.5-16.5\% uncorrected p-distance in ND2) from a population in the Zamboanga Peninsula of

126 Mindanao in the Philippines. This result suggests that the population in the Philippines represents

127 a hitherto undescribed species within the group.

128 In this study, we test whether divergence times between Sundaic populations of $E$.

129 rugifera correspond to periods of land connections across the Sunda Shelf during the Pleistocene,

130 suggesting that these land bridges allowed for dispersal across the Sunda Shelf, or if they predate

131 the late-Pliocene and Pleistocene climatic shift, indicating that E. rugifera faced barriers to 
132 dispersal on the Sunda Shelf despite land connections. The result has implications for the role

133 historical climatic and geographic processes have played in the evolutionary history in Eutropis

134 rugifera and other taxa on the Sunda Shelf.

135

136 Materials \& Methods

137

138 The dataset used for phylogenetic analysis included five protein coding markers: mitochondrial

139 ND2 (1029 bp), and nuclear BRCA1 (969 bp), BRCA2 (1227 bp), MC1R (660 bp) and RAG1

140 (1131 bp) amplified using polymerase chain reaction. Corresponding primers and annealing

141 temperatures are shown in Table 1. When combined with samples from GenBank, the total

142 dataset included 18 specimens of E. rugifera, with the Philippine samples treated as an outgroup

143 (based on Barley et al. 2015). All sequences are deposited on Genbank (see Table S1 for

144 Genbank accession numbers). Bayesian Inference (BI) was conducted in MrBayes v3.2.1

145 (Ronquist \& Huelsenbeck, 2003) and Maximum Likelihood (ML) analysis was conducted using

146 RAxML v8.1.15 (Stamatakis, 2014). All genes were concatenated and the appropriate

147 partitioning scheme for each analysis was determined using PartitionFinder v1.1.1 (Lanfear et

148 al., 2012) based on the Bayesian Information Criterion. For RAxML, the GTR $+\Gamma$ model was

149 specified for all partitions specified by PartitionFinder with 1,000 rapid bootstrap replicates to

150 determine nodal support. For MrBayes, the analysis was set for 50,000,000 generations, with 4

151 chains, and two independent runs. The first $25 \%$ of trees were discarded as burn-in from each

152 run, and the latter $75 \%$ of trees from both simultaneous runs were combined. For all Bayesian

153 analyses, adequate burn-in and convergence of the Markov chains was assessed by eye using 
154 Tracer v1.6 (Rambaut \& Drummond, 2013), and all ESS values were confirmed to be greater 155 than 200 (most were greater than 8000).

156 Divergence times were estimated on the 5-loci dataset using the program BEAST v1.8.2

157 (Drummond \& Rambaut, 2007). The results of PartitionFinder were modified to allow for 158 separate substitution rate estimations for each locus. This resulted in separate partitions for the

159 first, second, and third positions for ND2 and for each nuclear marker in separate partitions with 160 the first and second codon positions together, and the third codon position separate, for a total of

16111 partitions. All nuclear markers were run under the $\mathrm{HKY}+\Gamma$ model, and $N D 2$ was run using the $162 \operatorname{TrN}+\Gamma$ model as specified in PartitionFinder for BEAST. The priors were set as follows:

163 coalescent, constant population size tree prior; lognormal prior with standard deviation of 1 on 164 each of the relative codon rate priors. A strict clock rate was chosen for all of the markers, with 165 the substitution rate for the nuclear markers estimated relative to ND2. This was achieved by 166 placing a flexible uniform prior (from 0 to 1 ) on the nuclear substitution rates, and by sampling 167 the ND2 rates from a normal distribution with a mean of 0.00895 and a standard deviation of 1680.0025 (which spans the ND2 rates observed in many taxa; Barley et al. 2015). The Markov 169 chain was run for 50 million generations, and convergence and appropriate burn-in was assessed 170 in Tracer, as specified above.

171 Haplotype networks of the nuclear markers were generated in R (R Core Team, 2016)

172 using the pegas package (Paradis, 2010). Samples were organized based on locality, with

173 increased subdivisions in northern Borneo. Philippine samples were excluded from the analyses.

174 Networks were generated under a parsimony model, and alternative topologies are displayed by 175 dashed grey lines. 
176 Recently collected samples from Sarawak were collected and exported under permits

177 approved by the Sarawak Forestry Department (Research Permit NCCD.907.4.4(Jld.11)-68 and

178 Export Permit 15530). Collection and euthenization protocols were approved by the Villanova

179 University Institutional Animal Care and Use Committee (AS FY13-14 and AS FY17-02).

180

181 Results

182

183 The concatenated BI and ML topologies were nearly identical, except for one node within the

184 north Borneo clade (Fig. S1). Support values differed substantially, with the BI analysis showing

185 higher posterior probabilities. All analyses supported E. rugifera from Sundaland as

186 monophyletic and divergent from populations from Mindanao in the Philippines, as previously

187 reported by Barley et al. (2015). In all analyses, individuals from north Borneo represent a well-

188 supported clade. The BI and ML analyses supports the placement of the Peninsular Malaysian

189 samples as more closely related to Bornean samples and sister to the Mentawai archipelago

190 samples (Fig. S1). The topology in the timetree, however, places Peninsular Malaysian samples

191 sister to Mentawai Archipelago samples (Fig. 2).

192 There exist three divergent lineages of E. rugifera in north Borneo, one in central

193 Sarawak from Bintulu to Gunung Mulu National Park, one in far southwest Sarawak, in

194 Kuching, and a third in Sabah. The relationship between these clades is not well supported, but is

195 consistent among all analyses in showing the sample from Kuching sister to the central Sarawak

196 clade, and the sample from Sabah sister to all the Borneo samples. Divergence time estimates

197 place the split between these clades at well over 2 million years ago. The BI analysis places the

198 Kuching and the Danum Valley specimens together as sister to the central Sarawak clade. The BI 
199 and ML topologies do not recover strong support for these relationships, but the timetree shows 200 some support for these relationships (Fig. 2).

201 Divergence time estimates based on a strict molecular clock (Fig. 2) relative to the 202 mitochondrial marker show the $95 \%$ confidence interval of divergence between E. rugifera in 203 Sundaland and E. cf. rugifera in the Philippines to be 9.87-24.63 Ma. The crown Sundaland 204 clade dates back to 3.49-8.36 Ma, which predates the Pleistocene land-connections on the Sunda 205 Shelf. The crown node of the Bornean clade is dated to 3.49-8.36 Ma, and the crown node for 206 the split between the Peninsular Malaysia and Mentawai populations is at 3.18-7.57 Ma.

207 Haplotype networks show the varying levels of phylogenetic signal among the four 208 nuclear genes (Fig. 3), with $B R C A 1$ containing the highest genetic diversity, followed by $R A G 1$, $209 B R C A 2$, and $M C 1 R$. BRCA1 and RAG1 are consistent in showing similar haplotypes among 210 Peninsular Malaysian and Mentawai Archipelago samples. BRCA2 and MC1R show lower levels 211 of differentiation, with samples from across the range sharing $M C 1 R$ haplotypes. Nuclear trees

212 are not discordant with patterns shown in the concatenated tree, in general showing Peninsular 213 Malaysian and Mentawai Archipelago with divergent haplotypes from north Borneo samples 214 (also see Fig. S2)

216 Discussion

Our molecular clock dating estimates in E. rugifera, place the crown node for the Sunda 219 clade between 3.49-8.36 Ma, and this entire confidence interval predates the period of consistent 220 land connections on the Sunda Shelf (see Fig. 2). Monophyly of north Borneo and Peninsular

221 Malaysian samples further supports the hypothesis that these island populations have remained in 
222 isolation through the Pleistocene land connections, and deep divergences within north Borneo

223 samples suggest Pleistocene barriers may have existed not only on the Sunda Shelf, but on

224 Borneo as well. We cannot differentiate between mechanisms causing the initial cladogenesis

225 among populations on the Sunda Shelf without a time-calibrated tree with narrower confidence

226 intervals. Possible scenarios include vicariance during Pliocene fragmentation of the Sunda shelf

227 (Gorog et al. 2004), oceanic dispersal between islands during Pliocene periods of high sea-levels, 228 or population fragmentation during the Plio-Pleistocene climatic shift.

229 Ecological and physical barriers on the exposed Sunda Shelf during the Pleistocene may

230 have prevented gene flow across it for low and mid elevation rainforest adapted species. Multiple

231 lines of evidence suggest that the when exposed, the central Sunda Shelf supported an open

232 steppe habitat of grassland and savannah with mangrove forests and swamplands near the coast

233 (Gathorne-Hardy et al., 2002; Bird, Taylor \& Hunt, 2005; Cannon, Morley \& Bush, 2009; Louys

$234 \&$ Meijaard, 2010). Environmental models, however, have difficulty determining if an "arid

235 corridor" that would have completely separated LGM lowland evergreen rainforest on Borneo

236 from that on Peninsular Malaysian and Sumatra existed (Cannon, Morley \& Bush, 2009). Our

237 phylogeographic results are consistent with the hypothesis that the central core of the Sunda

238 Shelf was not suitable for E. rugifera, and gene flow was extremely limited even during periods

239 of Pleistocene land connections. As a rainforest adapted species, we suspect that E. rugifera was

240 unable to cross the exposed Sunda Shelf due to ecological unsuitability in this area, resulting in

241 divergence times that predate the Pleistocene (Fig. 2). Unfortunately, locality records of $E$.

242 rugifera limited and geographically clustered, many of which are not georeferenced accurately,

243 and therefore do not allow for adequate ecological niche models that can be projected on the

244 paleoclimate and which would allow for a more thorough understanding of the species' response 
245 to the historical conditions (Lim et al. 2011). Alternatively, if E. rugifera did not face ecological

246 barriers on the Sunda Shelf, then the incumbency of allopatric E. rugifera in the same

247 environmental niche could also have prevented panmixia (Kozak \& Wiens 2006). This is

248 possible if some level of reproductive isolation had evolved between populations on different

249 Sundaic landmasses, or if population sizes were large and/or if gene flow was limited temporally 250 and in magnitude during these periods.

Within the Borneo clade, we find some evidence of a population break between Sarawak

252 and Sabah, as well as between central Sarawak and western Sarawak. Genetic divergence

253 between populations in Sabah and Sarawak has been observed in many bird species (Moyle et

254 al., 2005; Sheldon et al., 2009; Hosner et al., 2010; Lim \& Sheldon, 2011; Lim et al., 2011;

255 Moltesen et al., 2012; den Tex \& Leonard, 2013; Gawin et al., 2014), in some frogs (Brown et 256 al., 2009, 2010; Arifin et al., 2011; Brown \& Siler, 2014), tree squirrels (den Tex et al., 2010), 257 honeybees (Tanaka et al., 2001), and in some trees (Kamiya et al., 2002; Ohtani et al., 2013), 258 however, it remains unknown what biogeographic barrier or historical process is causing this 259 divergence. In some cases, populations in western Sarawak are resolved as sister to populations 260 in Sumatra or Peninsular Malaysia (Lim et al., 2011), suggesting that these species were able to 261 cross the exposed Sunda Shelf, but faced stronger barriers to gene flow within Borneo. Our 262 results suggest that E. rugifera not only was unable to cross the Sunda Shelf during periods of 263 reduced sea-levels, but also faced strong barriers to gene flow within Borneo, as evidenced by 264 the deep divergences observed across northern Borneo.

265 Our phylogeographic results are consistent with Amarasinghe et al. (2017), who 266 recovered substantially divergent lineages on Bali and Bawean island (although they did not 267 estimate divergence times). If we were to combine the results of Amarasinghe et al. (2017) with 
268 our own (different genetic loci), it is possible that there are between three and six major clades of

269 Sundaic E. rugifera (and potentially even more from unsampled localities): 1.) Sumatra +

270 Nicobar Islands; 2.) Mentawai Archipelago; 3.) Peninsular Malaysia; 4.) Borneo; 5.) Bawean

271 Island; and 6.) Bali. Further genetic sampling may show close relationships between some of

272 these clades (e.g., Mentawai Archipelago closely related to Sumatra and the Nicobar Islands; or

273 Bawean Island closely related to the Borneo clade) and will shed light on the phylogeography

274 and evolutionary history of this species across the entire Sunda Shelf.

275 Modern herpetological collections in Indonesia have been sparse and large portions of the

276 country remain to be surveyed. Secretive species like E. rugifera, which are relatively difficult to

277 target when conducting fieldwork, will only be fully understood once a larger body of genetic

278 samples have accumulated from repeated surveys across Indonesia. In particular, samples from

279 Kalimantan are necessary to investigate the geographic structuring observed in Borneo, and

280 collections across the entire range of E. rugifera, especially from the Nicobar Islands, Sumatra,

281 and Java will help to fully understand the phylogeography of this species. The divergent and

282 geographically isolated lineages of E. rugifera uncovered here both within Borneo and across the

283 Sunda Shelf suggest that this species may be particular susceptible to divergence from

284 biogeographic forces, and further study of this species may lead to further insights into the

285 evolutionary processes causing cladogenesis on the Sunda Shelf.

286

\section{Acknowledgements}

288

289 We thank Haji Wan Shardini Wan Salleh, Engkamat Lading, Sapuan Ahmad and the Sarawak

290 Forestry Department for facilitating collecting and export permits. We thank graduate students 
291 Adi Shabrani and Pui Yong Min (Institute of Biodiversity and Environmental Conservation,

292 Universiti Malaysia Sarawak) and Jackie Childers and Ian Brennan (Villanova University) for

293 help in the field. Finally, we thank Jens Vindum and Lauren Scheinberg (CAS) for assistance

294 with the importation of specimens.

295

296 References

297

298

299

Amarasinghe AAT., Poyarkov Jr NA., Campbell PD., Leo S., Supriatna J., Hallermann J. 2017. Systematics of Eutropis rugifera (Stoliczka, 1870) (Squamata: Scincidae) including the redescription of the holotype. Zootaxa 4272:103-118. DOI: 10.11646/zootaxa.4272.1.5.

301

302

303

304

305

306

307

308

309

310

311

312

313

Arevalo E., Davis SK., Sites JW. 1994. Mitochondrial DNA sequence divergence and phylogenetic relationships among eight chromosome races of the Sceloporus grammicus complex (Phrynosomatidae) in central Mexico. Systematic Biology 43:387-418. DOI: 10.1093/sysbio/43.3.387.

Arifin U., Iskandar DT., Bickford DP., Brown RM., Meier R., Kutty SN. 2011. Phylogenetic relationships within the genus Staurois (Anura, Ranidae) based on 16S rRNA sequences. Zootaxa:39-52.

Bauer AM., Jackman TR., Greenbaum E., Giri VB., de Silva A. 2010. South Asia supports a major endemic radiation of Hemidactylus geckos. Molecular Phylogenetics and Evolution 57:343-352. DOI: 10.1016/j.ympev.2010.06.014.

Barley AJ., Datta-Roy A., Karanth KP., Brown RM. 2015. Sun skink diversification across the Indian-Southeast Asian biogeographical interface. Journal of Biogeography 42:292-304. DOI: $10.1111 /$ jbi.12397. 
314 Bird MI., Taylor D., Hunt C. 2005. Palaeoenvironments of insular Southeast Asia during the Last

315 Glacial Period: a savanna corridor in Sundaland? Quaternary Science Reviews 24:2228-

316 2242. DOI: 10.1016/j.quascirev.2005.04.004.

317 Bossuyt F., Meegaskumbura M., Beenaerts N., Gower DJ., Pethiyagoda R., Roelants K.,

318 Mannaert A., Wilkinson M., Bahir MM., Manamendra-Arachchi K., Ng PKL., Schneider

319 CJ., Oommen O V., Milinkovitch MC. 2004. Local Endemism Within the Western Ghats-

320 Sri Lanka Biodiversity Hotspot. Science 306:479-481. DOI: 10.1126/science.1100167.

321 Brown RM., Linkem CW., Siler CD., Sukumaran J., Esselstyn JA., Diesmos AC., Iskandar DT.,

322 Bickford D., Evans BJ., McGuire JA., Grismer L., Supriatna J., Andayani N. 2010.

323 Phylogeography and historical demography of Polypedates leucomystax in the islands of

$324 \quad$ Indonesia and the Philippines: Evidence for recent human-mediated range expansion?

325 Molecular Phylogenetics and Evolution 57:598-619. DOI: 10.1016/j.ympev.2010.06.015.

326 Brown RM., Siler CD. 2014. Spotted stream frog diversification at the Australasian faunal zone

327 interface, mainland versus island comparisons, and a test of the Philippine "dual-umbilicus"

328 hypothesis. Journal of Biogeography 41:182-195. DOI: 10.1111/jbi.12192.

329 Brown RM., Siler CD., Diesmos AC., Alcala AC. 2009. Philippine Frogs of the Genus

330 Leptobrachium (Anura; Megophryidae): Phylogeny-based Species Delimitation, Taxonomic

331 Review, and Descriptions of Three New Species. Herpetological Monographs 23:1-44.

332 DOI: $10.1655 / 09-037.1$.

333 Cannon CH., Morley RJ., Bush ABG. 2009. The current refugial rainforests of Sundaland are

334 unrepresentative of their biogeographic past and highly vulnerable to disturbance.

335 Proceedings of the National Academy of Sciences of the United States of America

336 106:11188-11193. DOI: 10.1073/pnas.0809865106. 
337 Das I. 2004. Lizards of Borneo: a pocket guide. Kota Kinabalu: Natural History Publications 338 (Borneo), Sdn Bhd.

339 Das I. 2010. A Field Guide to the Reptiles of South-east Asia. London: New Holland Publishers $340 \quad$ (UK), Ltd.

341 Datta-Roy A., Singh M., Srinivasulu C., Karanth KP. 2012. Phylogeny of the Asian Eutropis 342 (Squamata: Scincidae) reveals an "into India” endemic Indian radiation. Molecular 343 Phylogenetics and Evolution 63:817-824. DOI: 10.1016/j.ympev.2012.02.022.

344 Dersch M., Stein R. 1994. Late cenozoic records of eolian quartz flux in the Sea of Japan (ODP 345 Leg 128, Sites 798 and 799) and paleoclimate in Asia. Palaeogeography, 346 Palaeoclimatology, Palaeoecology 108:523-535. DOI: 10.1016/0031-0182(94)90250-X.

347 Dubey S., Keogh JS., Shine R. 2010. Plio-pleistocene diversification and connectivity between 348 mainland and Tasmanian populations of Australian snakes (Drysdalia, Elapidae, Serpentes). 349 Molecular Phylogenetics and Evolution 56:1119-1125. DOI:

$350 \quad$ 10.1016/j.ympev.2010.04.028.

351 Drummond A., Rambaut A. 2007. BEAST: Bayesian evolutionary analysis by sampling trees. 352 BMC Evolutionary Biology 7:1-8. DOI: 10.1186/1471-2148-7-214.

353 Gathorne-Hardy FJ., Syaukani., Davies RG., Eggelton P., Jones DT. 2002. Quaternary

354 Rainforest Refugia in Southeast Asia: using termites (Isoptera) as indicators. Biological 355 Journal of the Linnean Society 75:453-466.

356 Gawin DF., Rahman MA., Ramji MFS., Smith BT., Lim HC., Moyle RG., Sheldon FH. 2014.

357 Patterns of avian diversification in Borneo: the case of the endemic Mountain Black-eye 358 (Chlorocharis emiliae). The Auk 131:86-99. DOI: 10.1642/AUK-13-190.1.

359 Gorog AJ., Sinaga MH., Engstrom MD. 2004. Vicariance or dispersal? Historical biogeography 
of three Sunda shelf murine rodents (Maxomys surifer, Leopoldamys sabanus and Maxomys whiteheadi). Biological Journal of the Linnean Society 81:91-109.

362 Greaves SNJ., Chapple DG., Daugherty CH., Gleeson DM., Ritchie PA. 2008. Genetic

363 divergences pre-date Pleistocene glacial cycles in the New Zealand speckled skink,

364 Oligosoma infrapunctatum. Journal of Biogeography 35:853-864. DOI: 10.1111/j.1365$365 \quad 2699.2007 .01848 . x$.

366 Grismer LL., Wood PL., Cheol Haeng L., Quah ESH., Anuar S., Ngadi E., Sites JWJ. 2015. An

367 integrative taxonomic review of the agamid genus Bronchocela (Kuhl, 1820) from

368 Peninsular Malaysia with descriptions of new montane and insular endemics. Zootaxa $3693948: 1-23$.

370 Hall R. 2009. Southeast Asia's changing palaeogeography. Blumea: Journal of Plant Taxonomy 371 and Plant Geography 54:148-161. DOI: 10.3767/000651909X475941.

372 Hosner PA., Sheldon FH., Lim HC., Moyle RG. 2010. Phylogeny and biogeography of the Asian 373 trogons (Aves: Trogoniformes) inferred from nuclear and mitochondrial DNA sequences. $374 \quad$ Molecular Phylogenetics and Evolution 57:1219-1225. DOI:

$375 \quad$ 10.1016/j.ympev.2010.09.008.

376 Kamiya K., Harada K., Clyde MM., Mohamed AL. 2002. Genetic variation of Trigonobalanus 377 verticillata, a primitive species of Fagaceae, in Malaysia revealed by chloroplast sequences 378 and AFLP markers. Genes \& genetic systems 77:177-186. DOI: 10.1266/ggs.77.177.

379 Karin BR., Metallinou M., Weinell JL., Jackman TR. \& Bauer AM. (2016) Resolving the higher380 order phylogenetic relationships of the circumtropical Mabuya group (Squamata: 381 Scincidae): An out-of-Asia diversification. Molecular Phylogenetics and Evolution 382 102:220-232. DOI: 10.1016/j.ympev.2016.05.033. 
383 Kozak KH., Wiens JJ. 2006. Does niche conservatism promote speciation? A case study in North 384 American salamanders. Evolution 60:2604-2621. DOI: https://doi.org/10.1554/06-334.1.

385 Lanfear R., Calcott B., Ho SYW., Guindon S. 2012. PartitionFinder: Combined selection of 386 partitioning schemes and substitution models for phylogenetic analyses. Molecular Biology and Evolution 29:1695-1701. DOI: 10.1093/molbev/mss020.

Lim HC., Rahman MA., Lim SLH., Moyle RG., Sheldon FH. 2011. Revisiting Wallace's haunt: Coalescent simulations and comparative niche modeling reveal historical mechanisms that promoted avian population divergence in the malay archipelago. Evolution 65:321-334. DOI: $10.1111 /$ j.1558-5646.2010.01105.x.

Lim HC., Sheldon FH. 2011. Multilocus analysis of the evolutionary dynamics of rainforest bird populations in Southeast Asia. Molecular Ecology 20:3414-3438. DOI: 10.1111/j.1365294X.2011.05190.x.

Louys J., Meijaard E. 2010. Palaeoecology of Southeast Asian megafauna-bearing sites from the Pleistocene and a review of environmental changes in the region. Journal of Biogeography

Macey JR., Larson A., Ananjeva NB., Fang Z., Papenfuss TJ. 1997. 'ö̉iTwo novel gene orders and the role of light-strand replication in rearrangement of the vertebrate mitochondrial genome. Molecular Biology and Evolution 14:91-104.

Mausfeld P., Schmitz A. 2003. Molecular phylogeography, intraspecific variation and speciation 402 403 of the Asian scincid lizard genus Eutropis Fitzinger, 1843 (Squamata: Reptilia: Scincidae): taxonomic and biogeographic implications. Organisms Diversity \& Evolution 3:161-171. DOI: 10.1078/1439-6092-00068.

405 Miller KG., Kominz M a., Browning J V., Wright JD., Mountain GS., Katz ME., Sugarman PJ., 
406

407

408

409

410

411

412

413

414

415

416

417

418

419

420

421

422

423

424

425

426

427

428

Cramer BS., Christie-Blick N., Pekar SF., Miller KG., Kominz M a., Browning J V., Wright JD., Mountain GS., Katz ME., Sugarman PJ., Cramer BS., Christie-Blick N., Pekar SF. 2005. The Phanerozoic record of global sea-level change. Science 310:1293-1298. DOI: 10.1126/science. 1116412 .

Moltesen M., Irestedt M., Fjeldså J., Ericson PGP., Jønsson KA. 2012. Molecular phylogeny of Chloropseidae and Irenidae - Cryptic species and biogeography. Molecular Phylogenetics and Evolution 65:903-914. DOI: 10.1016/j.ympev.2012.08.012.

Moyle RG., Schilthuizen M., Rahman MA., Sheldon FH. 2005. Molecular phylogenetic analysis of the white-crowned forktail Enicurus leschenaulti in Borneo. Journal of Avian Biology 36:96-101. DOI: 10.1111/j.0908-8857.2005.03510.x.

Ohtani M., Kondo T., Tani N., Ueno S., Lee LS., Ng KKS., Muhammad N., Finkeldey R., Na’Iem M., Indrioko S., Kamiya K., Harada K., Diway B., Khoo E., Kawamura K., Tsumura Y. 2013. Nuclear and chloroplast DNA phylogeography reveals Pleistocene divergence and subsequent secondary contact of two genetic lineages of the tropical rainforest tree species Shorea leprosula (Dipterocarpaceae) in South-East Asia. Molecular Ecology 22:2264-2279. DOI: 10.1111/mec.12243.

Oshida T., Lin L-K., Chang S-W., Dang CN., Nguyen ST., Nguyen NX., Nguyen DX., Endo H., Kimura J., Sasaki M. 2017. Mitochondrial DNA Evidence Reveals Genetic Difference between Perny's Long-Nosed Squirrels in Taiwan and Asian Mainland. Mammal Study 42:111-116. DOI: 10.3106/041.042.0206.

Ota H. 1998. Geographic patterns of endemism and speciation in amphibians and reptiles of the Ryukyu archipelago, Japan, with special reference to their paleogeographical implications. Researches on Population Ecology 40:189-204. DOI: 10.1007/Bf02763404. 
429 Paradis E. 2010. Pegas: An R package for population genetics with an integrated-modular 430 approach. Bioinformatics 26:419-420. DOI: 10.1093/bioinformatics/btp696.

431 Pinho C., Rocha S., Carvalho BM., Lopes S., Mourão S., Vallinoto M., Brunes TO., Haddad 432 CFB., Gonçalves H., Sequeira F., Ferrand N. 2010. New primers for the amplification and 433 sequencing of nuclear loci in a taxonomically wide set of reptiles and amphibians.

434 Conservation Genetics Resources 2:181-185. DOI: 10.1007/s12686-009-9126-4.

435 Portik DM., Bauer AM., Jackman TR., Portik DM., Bauer AM., Jackman TR. 2010. The 436 phylogenetic affinities of Trachylepis sulcata nigra and the intraspecific evolution of 437 coastal melanism in the western rock skink. African Zoology 45:147-159.

438 QGIS Development Team. 2017. QGIS Geographic Information System. Open Source 439 Geospatial Foundation Project. DOI: http://www.qgis.org/.

440 Qi X-S., Yuan N., Comes HP., Sakaguchi S., Qiu Y-X. 2014. A strong “filter” effect of the East 441 China Sea land bridge for East Asia's temperate plant species: inferences from molecular 442 phylogeography and ecological niche modelling of Platycrater arguta (Hydrangeaceae). BMC Evolutionary Biology 14:41. DOI: 10.1186/1471-2148-14-41.

444 R Core Team. 2016. R: A Language and Environment for Statistical Computing. R Foundation 445 for Statistical Computing. DOI: ISBN 3-900051-07-0.

446 Rambaut A., Drummond AJ. 2013. Tracer V1.6. Available from http://beast.bio.ed.ac.uk/Tracer. 447 Ronquist F., Huelsenbeck JP. 2003. MrBayes 3: Bayesian phylogenetic inference under mixed 448 models. Bioinformatics 19:1572-1574. DOI: 10.1093/bioinformatics/btg180.

449 Sathiamurthy E., Voris KH. 2006. Maps of Holocene sea level transgression and submerged 450 lakes on the Sunda Shelf. The Natural History Journal of Chulalongkorn University 2:1-44. 451 Sheldon FH., Lohman DJ., Lim HC., Zou F., Goodman SM., Prawiradilaga DM., Winker K., 
452

453

454

455

456

457

458

459

460

461

462

463

464

465

466

467

468

469

470

471

472

473

474

Braile TM., Moyle RG. 2009. Phylogeography of the magpie-robin species complex (Aves:

Turdidae: Copsychus) reveals a Philippine species, an interesting isolating barrier and unusual dispersal patterns in the Indian Ocean and Southeast Asia. Journal of Biogeography 36:1070-1083. DOI: 10.1111/j.1365-2699.2009.02087.x.

Stamatakis A. 2014. RAxML version 8: A tool for phylogenetic analysis and post-analysis of large phylogenies. Bioinformatics 30:1312-1313. DOI: 10.1093/bioinformatics/btu033.

Steiper ME. 2006. Population history, biogeography, and taxonomy of orangutans (Genus: Pongo) based on a population genetic meta-analysis of multiple loci. Journal of Human Evolution 50:509-522. DOI: 10.1016/j.jhevol.2005.12.005.

Tanaka H., Roubik DW., Kato M., Liew F., Gunsalam G. 2001. Phylogenetic position of Apis nuluensis of northern Borneo and phylogeography of $A$. cerana as inferred from mitochondrial DNA sequences. Comparative and General Pharmacology 48:44-51. DOI: 10.1007/PL00001744.

den Tex RJ., Leonard JA. 2013. A molecular phylogeny of Asian barbets: Speciation and extinction in the tropics. Molecular Phylogenetics and Evolution 68:1-13. DOI: 10.1016/j.ympev.2013.03.004.

den Tex RJ., Thorington R., Maldonado JE., Leonard JA. 2010. Speciation dynamics in the SE Asian tropics: Putting a time perspective on the phylogeny and biogeography of Sundaland tree squirrels, Sundasciurus. Molecular Phylogenetics and Evolution 55:711-720. DOI: 10.1016/j.ympev.2009.12.023.

Voris HK. 2000. Maps of Pleistocene sea levels in Southeast Asia: shorelines, river systems and time durations. Journal of Biogeography 27:1153-1167. DOI: 10.1046/j.13652699.2000.00489.x. 
475 Woodruff DS., Turner LM. 2009. The Indochinese-Sundaic zoogeographic transition: A

476 description and analysis of terrestrial mammal species distributions. Journal of

477 Biogeography 36:803-821. DOI: 10.1111/j.1365-2699.2008.02071.x. 


\section{Table $\mathbf{1}$ (on next page)}

List of genes, primer names and sequences, references, and annealing temperatures used for each of the genes in this study. 


\begin{tabular}{cllc}
\hline Gene Primer Name & Reference & Primer Sequence (5'-3') & $\begin{array}{c}\text { Annealing } \\
\text { Temp. } \\
\left(\mathbf{~}^{\mathbf{C}} \mathbf{)}\right.\end{array}$ \\
\hline ND2 MetF1 & Macey et al. 1997 & AAGCTTTCGGGCCCATACC & 50 \\
CO1R1 & Arevalo et al. 1994 & AGRGTGCCAATGTCTTTGTGRTT & \\
BRCA1 BRCA1skink1804F & Karin et al. 2016 & YWTGGAGYTGAAYCCAGAAACTGATG & 56 \\
BRCA1skink3100R & Karin et al. 2016 & RKWGTCCTCAGAYKCATGWGACTGGG & \\
BRCA2 BRCA2skink984F & Karin et al. 2016 & AACAGGTAGTCAGTTTGAMTTYACAC & 56 \\
BRCA2skink2315R & Karin et al. 2016 & RTTGAAGYYTGAATGCYAGGTTTGAC & \\
MC1R MC1R.F & Pinho et al. 2010 & GGCNGCCATYGTCAAGAACCGGAACC & 54 \\
MC1R.R & Pinho et al. 2010 & CTCCGRAAGGCRTAAATGATGGGGTCCAC & \\
RAG1 RAG1skinkF2 & Portik et al. 2010 & TTCAAAGTGAGATCGCTTGAAA & 50 \\
RAG1skinkR2 & Portik et al. 2010 & AACATCACAGCTTGATGAATGG & \\
RAG1skinkF370 & Portik et al. 2010 & GCCAAGGTTTTTAAGATTGACG & \\
RAG1skinkR1200 & Portik et al. 2010 & CCCTTCTTCTTTCTCAGCAAAA & \\
\hline
\end{tabular}

1 


\section{Figure 1 (on next page)}

Map of the Sunda Shelf with $40 \mathrm{~m}$ and $120 \mathrm{~m}$ bathymetric contours.

Land connections on the Sunda Shelf form with a drop in sea level of just $40 \mathrm{~m}$ below present levels. During the last glacial maxima (LGM), sea levels in the area dropped to $120 \mathrm{~m}$ below present levels. The bold black shape indicates the range of Eutropis rugifera, including the presently recognized Philippines clade. Sampling localities of genetic samples used in this study are depicted by dots, and are color coded to match genetic clades inferred with the molecular analyses (Figs. 2-4). 


\section{Figure 2 (on next page)}

Divergence time estimates for Eutropis rugifera from analysis with BEAST.

Node labels show median node ages, with confidence intervals depicted by blue bars.

Posterior probabilities greater than or equal to 0.95 designated by a closed circle at the node.

The bold arrow shows the node of particular interest for the divergence of the Sundaic groups, and suggests divergence time across the Sunda Shelf that predates the PlioPleistocene transition. The "Climate" time-bar depicts the historical transition (gradient color, dashed gray bar above) from the mesic Miocene and Pliocene into the more xeric Pleistocene (see text for explanation). The "Land Connections" time-bar depicts the periods of time with sea level at least $40 \mathrm{~m}$ below present levels, when all major land-masses on the Sunda Shelf were connected (Miller et al., 2005). The frequency of the sea level shifts increased dramatically at the end of the Pliocene and throughout the Pleistocene. 
9.6- E. rugifera FMNH267951 - Samarakan

E. rugifera FMNH269713 - Sungai Mina

0.8 E. rugifera FMNH267950 - Samarakan

0.6 - E. rugifera FMNH273652 - Samarakan

3.0 羔 L. rugifera FMNH273653 - Samarakan

E. rugifera MOS131 - Mulu $\mathrm{HQ}$

Borneo

E. rugifera IDXX - Sarawak

0.8 E. rugifera LSUHC4067 - Niah Cave

E. rugifera FMNH269114 - Tabau

E. rugifera CAS259781 - Kuching

E. rugifera FMNH240613 - Danum Valley

0.9 E. rugifera LSUHC8929 - Gunung Panti Peninsular

E. rugifera LSUHC4003 - Kepong Malaysia

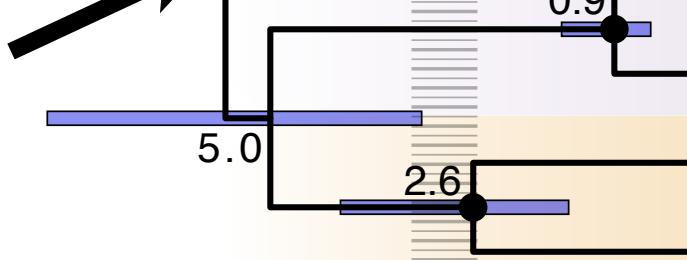

E. rugifera JAM10392 - Palau Siberut Mentawai

E. rugifera JAM10262 - Palau Nias Archipelago

0.1 E. rugifera KU315013 - Zamboanga, Philippines

E. rugifera KU321833 - Zamboanga, Philippines

Climate:

Sunda Shelf Land Connections:

Mesic

\section{Xeric}

\begin{tabular}{|l|l|l|} 
Miocene & Pliocene & Pleist. \\
15 & 5 & 1 \\
& & 10
\end{tabular}




\section{Figure 3 (on next page)}

Haplotype networks of Sundaic E. rugifera for four nuclear genes colored to correspond to the major clades and geographic locations in the concatenated analyses.

Haplotype circles are scaled to the number of specimens showing a haplotype. The number of hash-marks between circles denotes the number of nucleotide changes. 


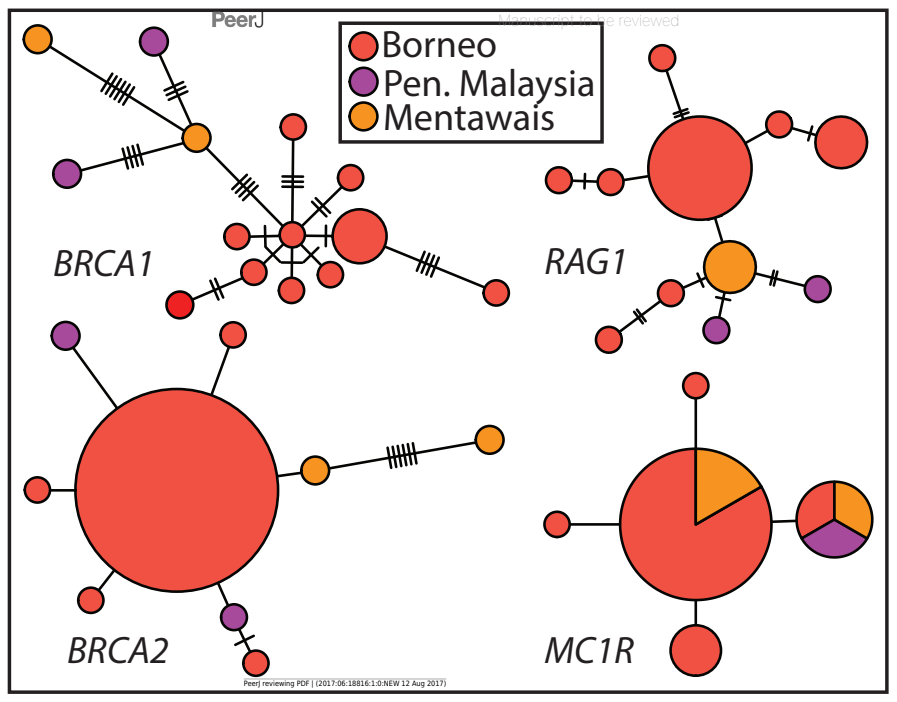

